\title{
Light comfort zone in a mesopelagic fish emerges from adaptive behaviour along a latitudinal gradient
}

\author{
Tom J. Langbehnn ${ }^{1, *}$, Dag L. Aksnes ${ }^{1}$, Stein Kaartvedt ${ }^{2}$, Øyvind Fiksen ${ }^{1}$, \\ Christian Jørgensen ${ }^{1}$
}

${ }^{1}$ Department of Biological Sciences, University of Bergen, Bergen 5020, Norway

${ }^{2}$ Department of Biosciences, University of Oslo, Oslo 0316, Norway

\begin{abstract}
Throughout the oceans, small fish and other micronekton migrate between daytime depths of several hundred meters and near-surface waters at night. These diel vertical migrations of mesopelagic organisms structure pelagic ecosystems through trophic interactions, and are a key element in the biological carbon pump. However, depth distributions and migration amplitude vary greatly. Suggested proximate causes of the migration such as oxygen, temperature, and light often correlate and therefore the causal underpinnings have remained unclear. Using mesopelagic fishes and the Norwegian Sea as a study system, we developed a dynamic state variable model that finds optimal migration patterns that we validate with acoustic observations along a latitudinal gradient. The model describes predation risk and bioenergetics, and maximizes expected energy surplus, a proxy for Darwinian fitness. The model allows us to disentangle the drivers of migration and make predictions about depth distribution and related fitness consequences along a latitudinal trajectory with strong gradients in environmental drivers and vertical distribution of scattering layers. We show that the model-predicted vertical migration of mesopelagic fishes matches that observed along this transect. For most situations, modelled mesopelagic fish behaviour can be well described by a light comfort zone near identical to that derived from observations. By selectively keeping light or temperature constant, the model reveals that temperature, in comparison with light, has little effect on depth distribution. We find that water clarity, which limits how deeply light can penetrate into the ocean, structures daytime depths, while surface light at night controlled the depth of nocturnal ascents.
\end{abstract}

KEY WORDS: Antipredation window · Deep scattering layer - Photoperiodic constraint hypothesis · High-latitude $\cdot$ Myctophidae $\cdot$ Twilight zone $\cdot$ Norwegian Sea $\cdot$ Benthosema glaciale

\section{INTRODUCTION}

The mesopelagic is the daytime twilight zone in the world oceans. The ecology here is a game of 'hide and seek', where organisms with limited swimming ability, e.g. micronekton such as small fish, crustaceans, and siphonophores, try to avoid encounters with larger predators, mainly bigger fish and squid. Mesopelagic micronekton are an important link in the pelagic food web (Dagorn et al. 2000, Connan et al. 2007, Naito et al. 2013) and might play a crucial role in mediating climate change effects through the sequestration of carbon into the deep ocean (Davi-

*Corresponding author: tom.langbehn@uib.no son et al. 2013, Aumont et al. 2018). Revised estimates suggest that the mesopelagic zone, from ca. 200-1000 m depth, harbours the majority of the global fish biomass (Irigoien et al. 2014). These diverse midwater assemblages make up the deep scattering layer (DSL), which is distributed across all major oceans from the tropics to sub-Arctic latitudes (Gjøsaeter \& Kawaguchi 1980, Sutton et al. 2017). While scattering layers may occur in Arctic waters, they are mostly attributed to advection from lower latitudes (Gjøsæter et al. 2017, Knutsen et al. 2017, Saunders et al. 2017), and mesopelagic biomass strongly declines towards the poles (Kristoffersen \&

(C) The authors 2019. Open Access under Creative Commons by Attribution Licence. Use, distribution and reproduction are unrestricted. Authors and original publication must be credited. 
Salvanes 1998, Siegelman-Charbit \& Planque 2016, Escobar-Flores et al. 2018).

In synchrony with the day-night cycle, the DSL rises and falls in the water column (Bianchi \& Mislan 2016), often spanning several hundred meters in depth (Klevjer et al. 2016). About half of all mesopelagic micronekton, possibly more than 5000 million tons, takes part in this diel vertical migration (Irigoien et al. 2014, Klevjer et al. 2016). This makes the daily vertical movements of mesopelagic organisms the largest migration of living biomass on the planet (Hays 2003).

The depth range of the DSL migration varies greatly (Bianchi et al. 2013, Klevjer et al. 2016). The daytime sound scattering layer is closer to the surface in the northern Indian Ocean, the central Atlantic Ocean, and the North and eastern tropical Pacific, than in the subtropical gyres, the central Indian Ocean, the western tropical and southeast Pacific, and the Pacific sector of the Southern Ocean (Bianchi et al. 2013, Klevjer et al. 2016). Some studies suggest these basin-scale patterns can be explained by the distribution of dissolved oxygen, with shallower migration depth in hypoxic areas (Koslow et al. 2011, Bianchi et al. 2013, Netburn \& Koslow 2015). Mesopelagic organisms forming the DSL, however, did not avoid oxygendepleted waters. In contrast, in areas with oxygen minimum zones, these mesopelagic organisms appeared at hypoxic or even anoxic depths (Tont 1976, Bianchi et al. 2013, Klevjer et al. 2016, Aksnes et al. 2017), suggesting no direct causation between their depth distribution and dissolved oxygen.

Light penetration has been pointed to as a parsimonious, mechanistic, and universal explanation for DSL depth distribution. Light was among the first drivers suggested to structure DSL depth (Kampa 1971, Dickson 1972, Tont 1976). Since then, various lines of evidence have converged on light being a first-order driver of DSL behaviour and therefore the most defining environmental factor for mesopelagic ecosystem structure (reviewed by Kaartvedt et al. 2019). For example, DSL species change their depth distribution in response to the lunar cycle (Benoit-Bird et al. 2009b, Wang et al. 2014, Prihartato et al. 2016) but also to short-term perturbations in light level from weather (Barham 1957, Kaartvedt et al. 2017), eclipses (Backus et al. 1965, Tont \& Wick 1973, Kampa 1975), and variations in waters of changing transparency (Abookire et al. 2002, Norheim et al. 2016). Full moon, cloudless skies, and clear water cause deeper nocturnal scattering layers, with ramifications through the food chain because of reduced predation on zooplankton in the upper waters (Hernández-León et al. 2010) and meso- pelagic fish being out of reach for many air-breathing predators (Horning \& Trillmich 1999, Benoit-Bird et al. 2009a).

When corrected for light attenuation, DSLs along a circumglobal transect were found within a narrow range of light intensities (Aksnes et al. 2017), also referred to as optical depth or light comfort zone (Røstad et al. 2016a,b). With better vision at dim light and operating at smaller spatial scales, mesopelagic fish might be able to exploit light comfort zones as an antipredation window, so that their search efficiency is maximized relative to the mortality risk from visually feeding piscivores (Clark \& Levy 1988, Scheuerell \& Schindler 2003). A proximate light comfort zone mechanism has been suggested to control DSL depth in the Norwegian Sea, but the potential role of temperature in governing DSL distribution patterns could not be excluded (Norheim et al. 2016).

Some fish species may use vertical migration as a strategy to exploit thermal gradients to optimize energy budgets. Feeding in warmer, food-rich surface waters but resting and digesting at colder depth can help conserve energy because metabolic costs increase at higher temperatures (Rosland \& Giske 1994, Sims et al. 2006). However, warmer waters also promote digestion, allowing fish to feed more and therefore grow faster (Wurtsbaugh \& Neverman 1988). Such trade-offs can result in diverse, statedependent migration and foraging strategies.

The deep scattering layer depth also varies with latitude (Beklemishev 1981). There are strong latitudinal gradients not only in temperature but also in seasonality of surface light and day length. Moving poleward, the distinct day-night light cycle gradually changes into a seasonal light regime with little variation in light intensities over the diel cycle. During the Arctic summer, the sun never sets, and it may not rise for months at a time during the polar night. These patterns have strong implications for the vertical extent of the twilight zone (Kaartvedt et al. 2019). Consistent with the assumption that light penetration structures vertical migration depth (Aksnes et al. 2017), the DSL was deeper during summer at higher latitudes, where observed migration was of smaller amplitude and not as distinct (Sobolevsky et al. 1996, Norheim et al. 2016).

In this study, we aim to quantify the role of light versus other drivers in structuring the depth distribution of mesopelagic fishes, with an emphasis on latitudinal gradients and the associated change in light regime towards high latitudes. Previous studies, most of them empirical, have described migration patterns and established correlations with potentially relevant driv- 
ers, pointing to light as the most dominant on a global scale (Aksnes et al. 2017). Here, we move beyond correlational inference from observational data and develop a theoretical and evolutionary model, built from simple, well-understood, and quantifiable mechanisms of visual encounters between prey and their predators (e.g. Eggers 1977, Aksnes \& Giske 1993) and temperature-dependent bioenergetics (e.g. Killen et al. 2010). We use observations from the Norwegian Sea as a case study and perform virtual experiments with our model to separate the effects of light from those of other environmental factors. In marine systems, light and temperature often co-vary across depth and latitude. In contrast to statistical modelling, a strength of our mechanistic approach is that it allows us to vary gradients of light and temperature independently to quantify their isolated effects on the optimal behavioural strategies. Our approach further allows us to identify both proximate and ultimate causes for the modelled vertical migration behaviour, thus generating testable hypotheses e.g. for how individual states such as gut fullness and energy reserves may covary with depths selected by mesopelagic fishes.

\section{MATERIALS AND METHODS}

\subsection{Study location and latitudinal gradients in the environment}

We use a detailed dataset of vertical CTD profiles and continuous (day and night) surface light measurements (Norheim et al. 2016) as direct drivers of the model (Fig. 1). Measurements were taken from May 1 to June 14,2013 , along a cruise track across the Nor- wegian Sea $\left(63.77^{\circ}-68.80^{\circ} \mathrm{N}\right)$, from the Norwegian shelf break in the southeast, across the Arctic Circle, to the Icelandic plateau in the northwest (Fig. 2A). Water temperature, water clarity, and surface light intensities all showed marked south-to-north gradients (Fig. 2B-D), and the timing was $1 \mathrm{wk}$ before the onset of the midnight sun period in the northernmost part of the transect. The gradient in the hydrography and light regime was associated with a deepening of the DSL and a decrease in the diel vertical migration amplitude at higher latitudes (Fig. 2E; echogram in the background).

\subsection{Model overview}

We use dynamic programming (Clark \& Levy 1988, Mangel \& Clark 1988, Houston \& McNamara 1999) to find state-dependent optimal life-histories and vertical migration behaviour of mesopelagic fish throughout the annual cycle in a 1D water column environment (Fig. 1). Similar optimization models have been used to predict vertical migration behaviour in other pelagic taxa, such as copepods (Fiksen \& Giske 1995), krill (Tarling et al. 2000, De Robertis 2002), and fish (Rosland \& Giske 1994).

The model is based on ecological mechanisms with emphasis on visual encounters between mesopelagic fishes and their prey and predators and the bioenergetics of feeding and digestion. First, the model finds the optimal behavioural decision for any state combination (gut fullness and energy reserves) as the choice of depth in that time step that maximizes expected lifetime surplus energy. This is a proxy for Darwinian fitness that takes into account both survival and the surplus of the energy budget that can
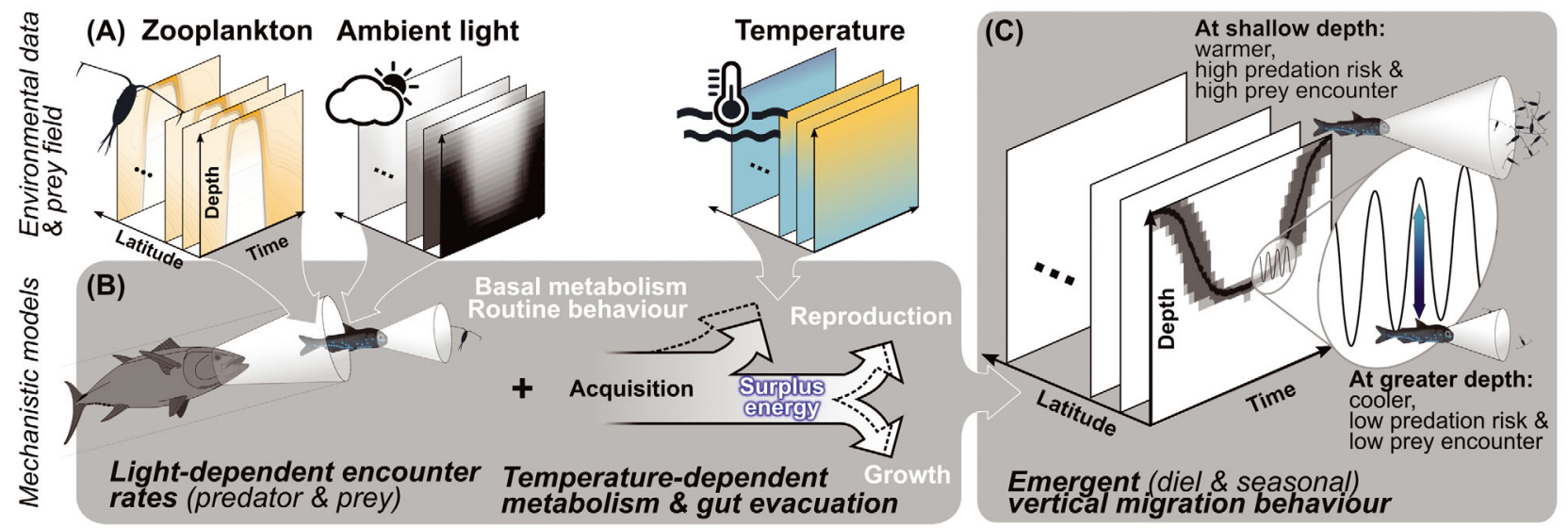

Fig. 1. Schematic overview of the state-dependent life history model, showing (A) how biotic and abiotic drivers are linked to (B) explicit mechanisms for temperature-dependent physiology and visual encounters to (C) predict optimal vertical migration behaviours using dynamic optimization 

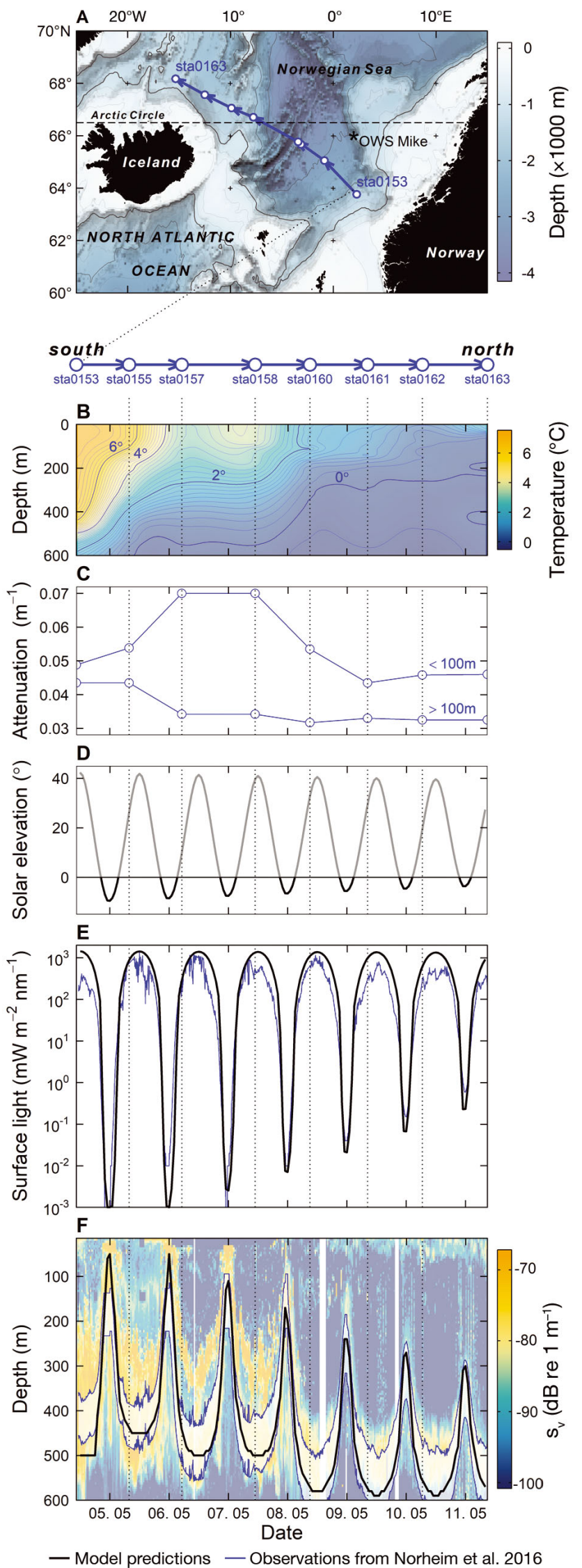

be used for growth or reproduction or otherwise contribute to fitness. The optimization algorithm is dynamic programming (Houston \& McNamara 1999, Clark \& Mangel 2000), an iterative procedure that first optimizes the last time step, then assumes the individual behaves optimally in the last time step and goes on to optimize the second-last time step, and so on backwards until it reaches the beginning of the time period considered. Thereafter, we simulate a population of single individuals as they follow the optimal behavioural strategies forward in time, and these emergent behaviours and the associated state dynamics are recorded, visualized, and analysed. We run the model for the full annual cycle to ensure consistent behaviours and state dynamics but show results only for the period in May for which we have observational data to compare with the model.

A full model description with all equations presented in detail is provided in the supplementary methods in Supplement 1 (see Supplements 1-3 at www.int-res. com/articles/suppl/m623p161_supp.pdf), along with model terms and parameters summarized in Table S1 in Supplement 2. Below, we provide a verbal summary.

\subsection{State dynamics}

We use 2 physiological states to describe mesopelagic fish: (1) reserve size, a metabolically active longterm energy store; and (2) gut fullness, the energy contained in the digestive system. State values are updated every time step, which in the current analysis is $1 \mathrm{~h}$. The gut dynamics are governed by consumption and digestion. Mesopelagic fish fill their guts by foraging and gut size constrains how much food can be consumed. Gut evacuation is temperature dependent, as higher temperatures increase the rate

Fig. 2. Model predictions (black lines) vs. observations (purple lines) made by Norheim et al. (2016) (A) Southeast-northwest cruise transect across the Norwegian Sea during May to June 2013. With increasing latitude (early to later dates), (B) water temperatures decreased, (C) water clarity increased, here shown as a decrease in light attenuation and $(D, E)$ the nights got brighter, associated with $(\mathrm{F})$ a deepening of the deep scattering layer (underlying echogram showing $38-\mathrm{kHz}$ volume backscattering strength $\mathrm{S}_{\mathrm{v}}$ from an EK60 echosounder). Using these empirical observations as environmental drivers, our model predicts optimal migration depth for the glacier lantern fish Benthosema glaciale (solid black line) that fit the observed backscatter distribution and predictions about a light comfort zone between $2.5 \times 10^{-7}$ and $1.6 \times 10^{-5} \mathrm{~mW} \mathrm{~m}^{-2} \mathrm{~nm}^{-1}$ at $486 \mathrm{~nm}$ (envelope marked by thin blue lines; see Norheim et al. 2016 and Fig. 3 therein). See Norheim et al. (2016) for a detailed description of the sampling 
at which consumed food is digested and energy is made available to the organism. Instantaneous metabolic demands, i.e. metabolic rate, also increase with temperature. If the net energy balance is negative then energy stores are drained, and individuals that have depleted their reserves die from starvation. If, however, the net energy balance is positive, reserves are replenished and once they are filled, remaining energy is allocated to surplus which in our model is the fitness proxy and thus what is maximized.

\subsection{Trade-offs}

Encounters with both prey and predators depend on vision (Eggers 1977, Aksnes \& Giske 1993). The pelagic habitat is characterized by steep vertical gradients, particularly in light which declines exponentially with depth. Visual foraging is therefore more efficient close to the surface. Foraging where or when there is more light to maximize encounter rates will, inherently, also increase the efficiency of other visual predators such as birds, squids and predatory fish, resulting in increased predation risk.

This trade-off is state-dependent. Life history theory predicts that starving individuals with empty guts and low reserves are more likely to accept risks, by exposing themselves to higher light intensities and predation risk, while a satiated individual can afford to shelter in the dark and digest its meal. Digesting in deep and dark waters reduces predation risk, but the deep is usually colder, which prolongs the time between foraging events. There is thus a trade-off between safe versus fast digestion, which affects survival and net energy gain and therefore is crucial to fitness.

\subsection{Backwards optimization and forward simulation}

Foraging and life history theory predicts that mesopelagic fish should reside at the depth that resolves the trade-offs arising along the depth axis. The common currency underlying behavioural decisions is fitness. Here, we define fitness as the expected surplus energy gain, i.e. the energy the individual potentially could channel towards reproduction if it avoids predation, thus offset by the probability that it remains alive.

The model finds optimal depth choices for all state and time combinations through backward iteration, starting well before and ending well after the period during which we compare with observations. This ensures that behaviours and state dynamics are internally consistent so what we report reflects the dynamics of the modelled ecology and not assumptions about model initialization or terminal effects (see Houston \& McNamara 1999).

Vertical migration strategies then emerge from the model once we simulate the optimal state-dependent depth positions forward in time, using observation from the cruise as environmental drivers. We run $100 \mathrm{yr}$ in the forward simulation and show the last year to avoid effects of assumed initial states.

During optimization and forward simulation, we use environmental values observed during the cruise, or we treat the model as a virtual laboratory and vary environmental drivers in 'what if' scenarios to study effects of single factors.

\subsection{Resolution}

Each time step of the model corresponds to $1 \mathrm{~h}$ and we model the behaviour for the full annual cycle. Fish can migrate and adjust their vertical position by up to $100 \mathrm{~m}$ per time step (corresponding to a vertical migration speed of $0.03 \mathrm{~m} \mathrm{~s}^{-1}$ ), and the model is constrained between the surface and $1000 \mathrm{~m}$ depth. We compute the light environment for every time step, whereas we update zooplankton densities and their vertical distribution daily. Apart from CTD casts taken along the cruise track we lack temperature observation. Therefore, we resorted to the simplifying assumption that temperature profiles were constant through the year, which was expected to have little impact on predicted behaviours because we only show and analyse results for the one week in May where the temperatures were actually observed. We note that running the model with temperature climatologies from the World Ocean Atlas instead did not affect the migration behaviour for the current parametrisation and time window.

\subsection{Model validation}

The observational dataset (Norheim et al. 2016) provides a unique opportunity to test the influence of light on DSL depth and to validate our model for a range of environmental settings. Continuous light measurements, including nocturnal illumination, alongside acoustic observations and other relevant environmental factors (e.g. temperature) allowed for the rare opportunity of a one-to-one comparison of model predictions with observations, across environ- 
mental gradients and down to an hourly resolution. Here, we combined 8 model runs to cover the full latitudinal gradient from $63.77^{\circ}$ to $68.80^{\circ} \mathrm{N}$ (Fig. 2A). At each discrete latitude, we ran the model for the full annual cycle of $365 \mathrm{~d}$. We then selected a single day from every run, beginning with May 3 and progressing to May 11 with increasing latitude, and merged them to a continuous transect to compare with observations. Because we could anchor our model to observations, with high time resolution, across latitude, and changing environmental settings such as brighter nights above the Arctic Circle, validating against this dataset increases confidence in future predictions made for other localities and times of the year.

\subsection{Species ecology and model parametrization}

We chose parameter values representing Benthosema glaciale, the dominant mesopelagic fish in the Norwegian Sea. We consider fish of average adult size of $6 \mathrm{~cm}$ length (Gjøsæter 1981), feeding on calanoid copepods of $2.7 \mathrm{~mm}$ length. The size of the copepod prey was chosen in accordance with dietary studies on B. glaciale from the North Atlantic (Pepin 2013), and to match the size of Calanus finmarchicus (CV-CVI), C. glacialis (CIV-CV), and C. hyperboreus (CIII), dominating the zooplankton biomass in the Norwegian Sea (Melle et al. 2004).

Zooplankton abundances and distributions along the cruise track were unknown. Therefore, we used the best available data from literature, i.e. long-term studies conducted at weather ship station Mike (Østvedt 1955, Heath et al. 2000, Melle et al. 2004, 2014) and seasonal studies form the Icelandic Sea (Gislason \& Silva 2012, Gislason 2018), to outline an idealised prey-field with seasonal dynamics for the southern Norwegian Sea (Fig. A1 in the Appendix). In our scenario, prey densities in surface waters peak around 500 ind. $\mathrm{m}^{-3}$ during June and decline to around 3 ind. $\mathrm{m}^{-3}$ in September when copepods have dispersed and the majority has descended to depth for hibernation (Gislason 2018). The lowest densities, around 0.1 ind. $\mathrm{m}^{-3}$, occur below $450 \mathrm{~m}$ during the summer bloom (Fig. A1B). The total numbers of copepods varied seasonally between 3200 and 16000 ind. $\mathrm{m}^{-2}$, declining continuously after the population peak in June until late May the next year when abundance sharply increases again due to reproduction (Fig. A1A). A range of predators, including fish, marine mammals and seabirds, prey upon myctophids in the upper water column (Connan et al. 2007, Stewart et al. 2018). Predation at DSL daytime depth may be less efficient and require extraordinary physiological adaptations of epipelagic predators (Dagorn et al. 2000, Naito et al. 2013, Drazen \& Sutton 2017). Here we focus on visual predators that are generally more efficient during daytime and closer to the surface. We assume predation by a teleost predator of $50 \mathrm{~cm}$ length with local densities of $5 \times 10^{-5}$ ind. $\mathrm{m}^{-3}$. In our model, temperature and light are the main environmental drivers. We do not account for oxygen, but here dissolved oxygen is not a likely constraint, because the study area is welloxygenated (Norheim et al. 2016). We use vertical temperature measurements along the cruise track (Norheim et al. 2016) as direct input to the model but simulate surface light tuned to observations to prevent the optimization algorithm from exploiting artefacts in the light measurements, e.g. periods of overcast, and obscuring more general patterns. The difference between observed and simulated light values is shown in Fig. 2E. Currently the model does not account for variation in nocturnal illumination due to the lunar cycle, but we test our model predictions for typical nocturnal light intensities ranging from overcast to moonlit nights, a variation of $\sim 5$ orders of magnitude in light intensities at the surface (Table S2G in Supplement 3). Adding an explicit model for the lunar light cycle in a future version of the model is uncomplicated.

We initiate fish at $500 \mathrm{~m}$ depth, with both gut and energy reserves filled completely.

\subsection{Sensitivity analysis}

We ran 2 types of sensitivity analyses. First, we used one-factor-at-a-time sensitivity analysis with $\pm 20 \%$ variation in default parameter values to confirm that our predictions were robust to variation in environmental, ecological, and physiological parameters. For the most poorly constrained variables, such as predator density or eye sensitivity, we extended the testing over a much wider range of parameter values (see Table S2). In total, we tested model sensitivity to 31 parameters, resulting in 83 model runs. Secondly, we tested the effect of removing latitudinal gradients in the environment, which will help us disentangle the relative effects of specific drivers on the predicted vertical migration behaviour. We used a factorial design with temperature, water clarity, and surface light as factors. We removed latitudinal gradients by substituting the changing environments along the cruise track with the same temperature, light or optical conditions for all latitudes. For that we 
used the light and optical conditions from the start of the transect, and fixed temperature to $7^{\circ} \mathrm{C}$, which consequently also removed the vertical temperature gradient.

\section{RESULTS}

\subsection{Confronting model predictions with observations}

The model predicts the depth and vertical movements of the DSL with high fidelity to observations (Fig. 2F), and was robust to variation in initial parameter choice (Fig. S1 and Table S2 in Supplement 3). Although 2 unknown parameters related to eye sensitivity were tuned to match observed depth distributions, the model predicted several other and partly unrelated patterns that suggest the included mechanisms are indeed the ones driving most of the behaviour. These patterns were, first a gradual deepening of the DSL from around $450 \mathrm{~m}$ daytime depth at latitudes $<65^{\circ} \mathrm{N}$, to almost $600 \mathrm{~m}$ at $68^{\circ} \mathrm{N}$. Second, nighttime ascents reached $50 \mathrm{~m}$ in the south, but were restricted to $300 \mathrm{~m}$ depth at the northernmost station. The migration amplitude was thus truncated by around $100 \mathrm{~m}$ at higher latitudes, because the deepening of the scattering layer distribution was more pronounced at night than during day (Fig. 2F).

The deepening of the DSL correlated with a latitudinal change in light regime (Fig. 2D). During the 8-d cruise crossing the Arctic Circle, nights grew shorter, from around $7 \mathrm{~h}$ between sunset and sunrise in the south to around $4 \mathrm{~h}$ in the north. In part, this increase in day length was due to progressing dates. North of the Arctic Circle, civil twilight persisted through the night, with nocturnal light intensities 3 orders of magnitude higher than at the beginning of the transect (Fig. 2E).

\subsection{Deep scattering layer depth in relation to light}

The migration depth of the modelled fishes was highly responsive to changes in the environment, particularly light (Fig. 3). Along the cruise track there was clearer water towards the north (Fig. 2C), and light therefore penetrated deeper, which explained change of the observed daytime depth of the DSL. When the more turbid water from the southernmost station was applied in the model throughout an otherwise equal transect, the observed daytime deepening towards higher latitudes no longer occurred in the simulation (Fig. 3C; solid grey line). Another effect of light was the arrest of nighttime ascents at greater depths with increasing latitude, which in the model resulted from brighter nights (Fig. 3B; solid grey line).

In a scenario run where we controlled for both light and water clarity, nighttime depth shifted closer to the surface under higher temperatures (Fig. 3D; dashed red line). Although in this scenario we removed all latitudinal variation in surface light, water clarity and temperature, progressing date and therefore brighter nights closer to midsummer caused a continued shallowing of nighttime distribution. On average, our model predicted the DSL to deepen by $68 \mathrm{~m}$ for each order of magnitude increase in surface light at midnight, which is consistent with observations (Fig. 4A; solid versus broken regression lines). The model predicted crepuscular migrations that were synchronised with incoming solar radiation. This resulted in constant ambient light levels for the fishes (Fig. 4B) despite several orders of magnitude variation in surface light. The model predicted a relatively narrow light comfort zone between $1.6 \times 10^{-6}$ and $2.1 \times 10^{-6} \mathrm{~mW} \mathrm{~m}^{-2} \mathrm{~nm}^{-1}$ at $486 \mathrm{~nm}$, calculated as light intensity in the $25 \%$ to $75 \%$ quantile range, and an average of $1.9 \times 10^{-6} \mathrm{~mW} \mathrm{~m}^{-2} \mathrm{~nm}^{-1}$ at $486 \mathrm{~nm}$.

\subsection{Deep scattering layer depth in relation to temperature}

Our simulations showed that temperature was of minor importance in controlling depth distribution of the observed DSL (Fig. 3A). Temperature had practically no influence on the simulated DSL daytime depth and minor influence on nighttime depth. Only in a strongly stratified water column, as found at the southernmost part of the transect (Fig. 2B; see May 4), did the model suggest that there was an opportunity for mesopelagic fish to exploit temperature gradients by descending below the thermocline. This would bring them deeper than what could have been expected from ambient light and the light comfort zone (Figs. 2B,F \& 3), to reduce metabolic loss in cold water. Migrations below the thermocline were, however, not evident from the observations. With increasing temperatures, nighttime depth distributions shifted closer to the surface, particular at times when bright summer nights constrained mesopelagic fish to greater depth at night (Fig. 3).

Predicted ambient temperatures, averaged over a full $24 \mathrm{~h}$ diel vertical migration cycle, closely tracked the general decline in temperatures towards the 

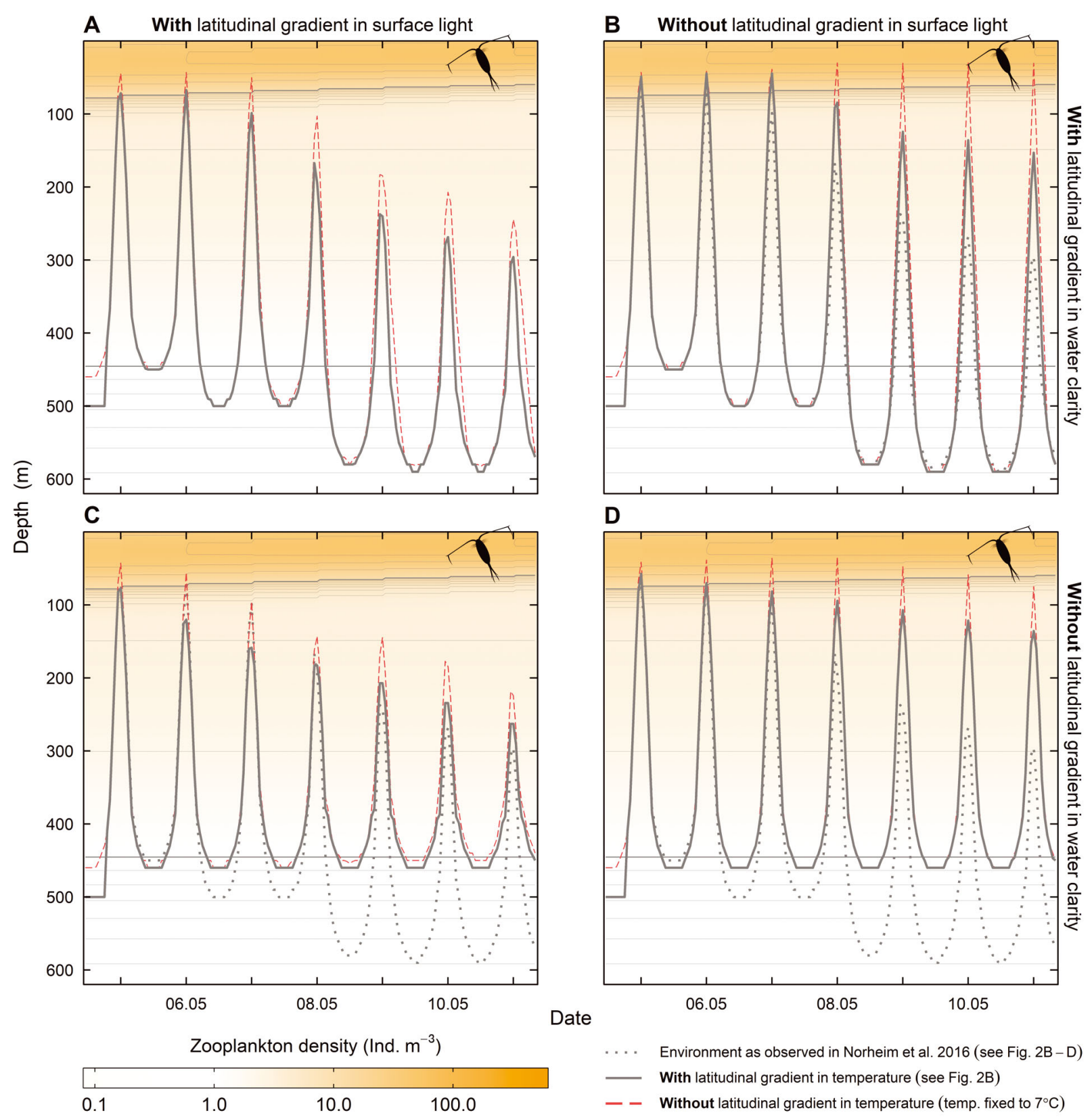

Fig. 3. (A) Modelled optimal migration depth of Benthosema glaciale with (solid grey lines) or without (dashed red lines) latitudinal temperature gradients, for the default light environment with surface light and water clarity as observed in Norheim et al. (2016) in comparison with model runs where latitudinal gradients were eliminated in either (B) surface light, or (C) water clarity here entering as light attenuation, or (D) both.

north (Fig. 3D). The range of experienced temperatures during diel vertical migration differed for latitudes below and above the Arctic Circle. Below the Arctic Circle, experienced temperatures reached the upper temperature extremes in the environment but never extended into the coldest waters. The opposite was true for latitudes above the Arctic Circle (Fig. 3D).

\section{DISCUSSION}

Our model shows that the timing, depth range, and amplitude of vertical migration of DSL in the Norwegian Sea are primarily driven by ambient light. Running the model with only the thermal gradient in the water column gave no diel vertical migration, nor could the latitudinal temperature gradient alone 

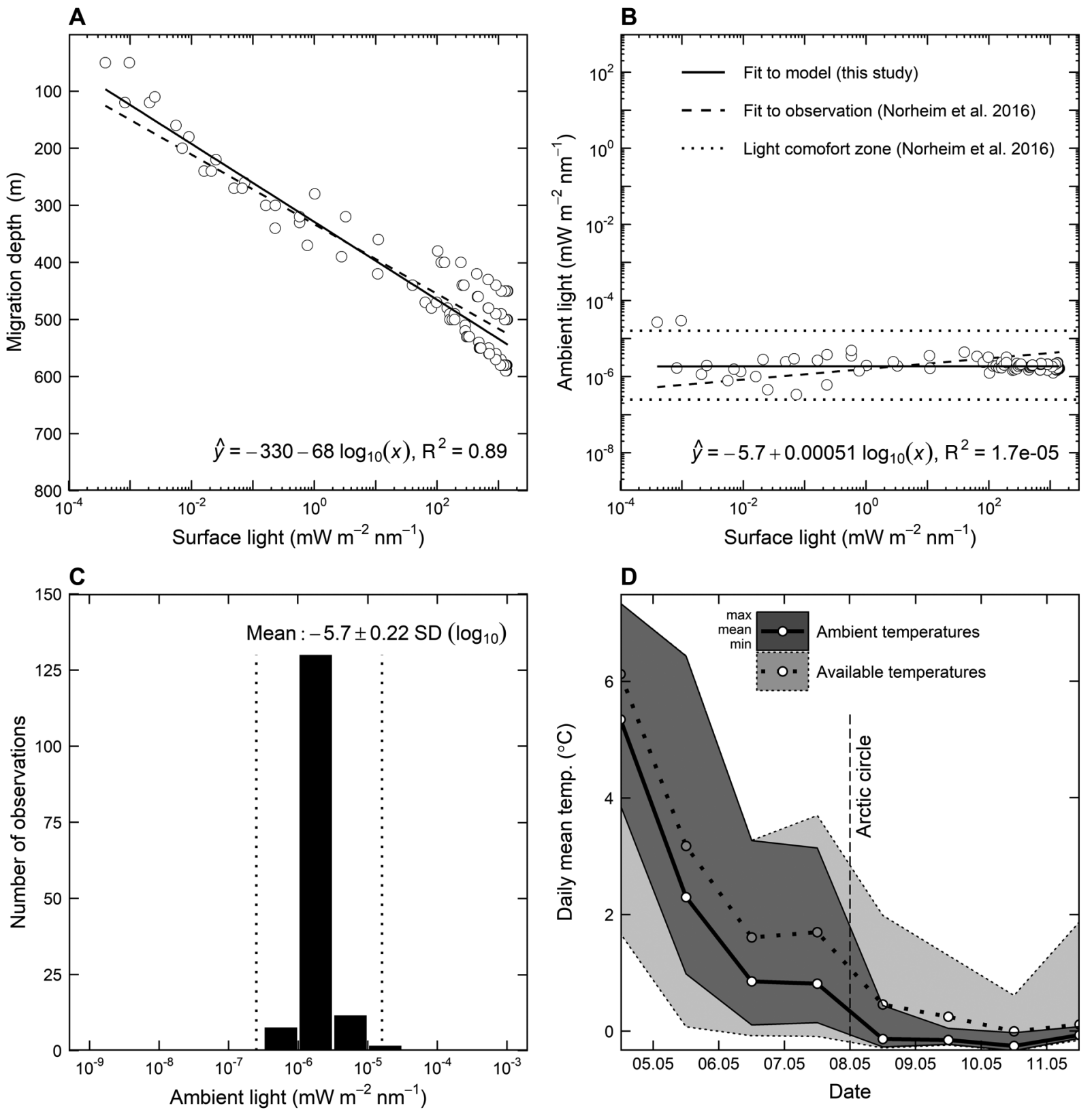

Fig. 4. (A) Predicted vertical migration depth of Benthosema glaciale, and (B) ambient light for a given depth as a function of surface light $\left(\mathrm{mW} \mathrm{m}^{-2} \mathrm{~nm}^{-1}\right.$ at $486 \mathrm{~nm}$ ). Models (solid line) are compared with observations (dashed line) from Norheim et al. (2016; see their Fig. 4). (C) The model predicts mesopelagic fish to adhere to a narrow range of light intensities around $1.9 \times$ $10^{-6}\left(=10^{-5.7}\right) \mathrm{mW} \mathrm{m}^{-2} \mathrm{~nm}^{-1}$ at $486 \mathrm{~nm}$. On average, vertical distribution deepened by $68 \mathrm{~m}$ for every order of magnitude increase in surface light (solid line in A). (D) The average ambient (experienced) temperatures during a diel vertical migration cycle were close to the available temperature in the environment

explain the observed deepening of the scattering layer. Our findings apply to the Norwegian Sea, and although we expect similar results for other high-latitude ecosystems, the minor effect of temperature on migration depth remains to be confirmed in places where the water column is more thermally stratified.
Ambient light is the product of surface irradiance and light attenuation with depth. Near the surface, ambient light is largely determined by the light input, while with increasing depth remaining light is primarily a result of water clarity, because light attenuation is an exponential process. Therefore, de- 
creased attenuation and clearer water is the main driver of the general daytime deepening of the observed DSL distribution, while the brighter nights (more incoming light at high latitudes in summer) cause the observed deeper nighttime distributions.

We predict the scattering layer depth to deepen by $68 \mathrm{~m}$ for each 10-fold increase in surface light, which is close to an estimate of $61 \mathrm{~m}$ based on acoustic observations from the same trajectory in the Norwegian Sea (Norheim et al. 2016). Observations from the northern end of the transect further support our predictions that with increasing latitude, the DSL during summer becomes increasingly constrained to greater depth, and vertical ascents at night are arrested several hundred meters below the surface, a behaviour that has been observed in previous studies (Sameoto 1989, Sobolevsky et al. 1996, Siegelman-Charbit \& Planque 2016, Gjøsæter et al. 2017, Knutsen et al. 2017).

For our parameterization of the myctophid Benthosema glaciale, the simulations predict optimal ambient light intensities around $1.9 \times 10^{-6} \mathrm{~mW} \mathrm{~m}^{-2} \mathrm{~nm}^{-1}$ at $486 \mathrm{~nm}$, which is near identical to ambient irradiance of $2.0 \times 10^{-6} \mathrm{~mW} \mathrm{~m}^{-2} \mathrm{~nm}^{-1}$ at $486 \mathrm{~nm}$ at the median DSL depth calculated based on observations (Norheim et al. 2016). When integrated over the spectrum, this corresponds to a total ambient irradiance of $1.9 \times 10^{-7} \mu \mathrm{mol}$ quanta $\mathrm{m}^{-2} \mathrm{~s}^{-1}$ (Norheim et al. 2016), which matches observations from a global transect, predicting a light comfort zone around $10^{-7} \mu \mathrm{mol}$ quanta $\mathrm{m}^{-2} \mathrm{~s}^{-1}$ with a span from $10^{-6}$ to $10^{-9} \mu \mathrm{mol}$ quanta $\mathrm{m}^{-2} \mathrm{~s}^{-1}$ at the 25 and $75 \%$ quartile DSL depths (Aksnes et al. 2017).

We find that the light comfort zone of mesopelagic fish is largely driven by the lower light sensitivity threshold of the eye of their predators (Table S2E). Our model predicts mesopelagic fish to choose safe depths at light intensities that are just below this threshold value, explaining also why increasing the predator density by one order of magnitude did not affect the modelled migration behaviour (Table S2F). Without visual predators, our model predicts diel vertical migration to cease and mesopelagic fish to remain close to the surface day and night.

Our predictions about a narrow light comfort zone could lead to the misguided interpretation that mesopelagic organisms should form dense aggregations. One caveat of optimality models is, however, the difficulty of accounting for density dependence (Houston \& McNamara 1999). In an environment with limited resources, and where aggregations make the prey an easier target for predators, deviating from the apparent optimal strategy might increase fitness. Therefore, predicted optimal strategies must be understood as population means, and observed light comfort zones might be wider than our predictions when such density-dependent effects are factored in. Additionally, light comfort zones will differ between species, length classes, and different predator-prey pairings due to differences in the light thresholds of their visual systems, of which we model only one. These differences may further contribute to the broad DSLs as seen from acoustic observations and may explain the co-occurrence of multiple scattering layers with discrete vertical distributions (Røstad et al. 2016a,b).

Temperature is certainly the environmental factor most widely invoked in explaining species distributions (Burrows et al. 2011, Sunday et al. 2012), and has been shown, among others, to be a proximate cause for vertical migration depth in fish (Levy 1990, Sims et al. 2006, Busch et al. 2011) and copepods (Fiksen \& Giske 1995, Bandara et al. 2018 and references therein). For the Norwegian Sea, however, we found little evidence for a temperature optimum or a bioenergetic basis of migration depth in mesopelagic fishes. The DSL depth was largely independent of temperature, and diel vertical migration emerged as the optimal fitness-maximizing strategy in the absence of vertical or latitudinal temperature gradients (Figs. 2B,F \& 3). Environments with steep temperature gradients might be the exception. In this case, migrating to the cold side of the thermocline could reduce metabolic costs, in particular if prey is limiting (Fig. 2B; see 4 May).

Species in terrestrial and marine systems may respond to global warming by shifting their distribution, not only laterally but also to higher elevations on land or larger depths in the oceans to remain within their preferred temperature range (Dulvy et al. 2008, Pinsky et al. 2013, Fossheim et al. 2015). Our model predicts a shift to shallower and warmer waters under increased temperatures (Fig. 3), which may hence seem counterintuitive at first. However, if mesopelagic fishes would follow a preferred temperature to greater depths, they would experience fewer prey per volume together with dimmer light, which would reduce encounter rates, while metabolic costs remain unchanged. In contrast, by shifting distributions closer to the surface, where there are more prey and light, they will increase encounter rates and thus sustain the higher metabolic demands of warmer waters, but at the cost of higher predation risk.

Understanding mesopelagic distribution has also been the focus of recent attempts to classify the global biogeography of the mesopelagic zone (Proud et al. 2017, Sayre et al. 2017, Sutton et al. 2017, Rey- 
gondeau et al. 2018). These global studies, and recent work predicting future distributions of lanternfish at high latitudes (Freer et al. 2019), have focused on temperature, salinity, primary production, and surface wind stress as environmental drivers, but have not included light despite a long history of compelling observational studies (i.a. Kampa 1971, Dickson 1972, Tont 1976, Aksnes et al. 2017). Therefore, one important insight that follows from our model analysis is that we currently do not routinely measure and consider what emerges as the first order driver of mesopelagic ecology, namely ambient light. Because temperature is routinely measured or is easily available from hydrographic databases or models, it is, almost without exception, included as an explanatory variable in all contemporary marine studies. Light data is, in contrast, sparsely available, particularly nighttime values (Kaartvedt et al. 2019). There is consequently a need for in situ light measurements, at the surface and down to mesopelagic depths, and for studying visual capacity and particular spectral sensitivity of mesopelagic organisms.

We conclude by repeating Dickson $(1972$, p. 417): 'it is clear in each case that these controls [referring to temperature and oxygen] are no more than modifying influences on migration patterns that are primarily influenced by illumination'.

Acknowledgements. We thank Thor Klevjer for providing acoustic data from the EUROBASIN cruise. Michael Burrows, Xabier Irigoien, and the reviewers are thanked for providing critical and constructive feedback. T.J.L., C.J. and Ø.F. received funding through the MARmaED project from the European Union's Horizon 2020 research and innovation programme under the Marie Skłodowska-Curie grant agreement No. 675997. The results of this publication reflect only the author's view and the Commission is not responsible for any use that may be made of the information it contains.

\section{LITERATURE CITED}

Abookire AA, Piatt JF, Speckman SG (2002) A nearsurface, daytime occurrence of two mesopelagic fish species (Stenobrachius leucopsarus and Leuroglossus schmidti) in a glacial fjord. Fish Bull 100:376-380

Aksnes DL, Giske J (1993) A theoretical model of aquatic visual feeding. Ecol Model 67:233-250

*Aksnes DL, Røstad A, Kaartvedt S, Martinez U, Duarte CM, Irigoien X (2017) Light penetration structures the deep acoustic scattering layers in the global ocean. Sci Adv 3: e1602468

Aumont O, Maury O, Lefort S, Bopp L (2018) Evaluating the potential impacts of the diurnal vertical migration by marine organisms on marine biogeochemistry. Global Biogeochem Cycles 32:1622-1643

Backus RH, Clark RC, Wing AS (1965) Behaviour of certain marine organisms during the solar eclipse of July 20, 1963. Nature 205:989-991
Bandara K, Varpe Ø, Ji R, Eiane K (2018) A high-resolution modeling study on diel and seasonal vertical migrations of high-latitude copepods. Ecol Model 368:357-376

Barham EG (1957) The ecology of sonic scattering layers in the Monterey Bay area, California. Hopkins Mar Stn Tech Rep No. 1, Stanford University, Pacific Grove, CA

*Beklemishev CWW (1981) Biological structure of the Pacific Ocean as compared with two other oceans. J Plankton Res 3:531-549

*Benoit-Bird KJ, Dahood AD, Würsig B (2009a) Using active acoustics to compare lunar effects on predator-prey behavior in two marine mammal species. Mar Ecol Prog Ser 395:119-135

Benoit-Bird KJ, Au WWL, Wisdoma DW (2009b) Nocturnal light and lunar cycle effects on diel migration of micronekton. Limnol Oceanogr 54:1789-1800

* Bianchi D, Mislan KAS (2016) Global patterns of diel vertical migration times and velocities from acoustic data. Limnol Oceanogr 61:353-364

* Bianchi D, Galbraith ED, Carozza DA, Mislan KAS, Stock CA (2013) Intensification of open-ocean oxygen depletion by vertically migrating animals. Nat Geosci 6:545-548

* Burrows MT, Schoeman DS, Buckley LB, Moore P and others (2011) The pace of shifting climate in marine and terrestrial ecosystems. Science 334:652-655

Busch S, Johnson BM, Mehner T (2011) Energetic costs and benefits of cyclic habitat switching: a bioenergetics model analysis of diel vertical migration in coregonids. Can J Fish Aquat Sci 68:706-717

C Clark CW, Levy DA (1988) Diel vertical migrations by juvenile sockeye salmon and the antipredation window. Am Nat 131:271-290

Clark CW, Mangel M (2000) Dynamic state variable models in ecology. Oxford University Press, New York, NY

* Connan M, Cherel Y, Mayzaud P (2007) Lipids from stomach oil of procellariiform seabirds document the importance of myctophid fish in the Southern Ocean. Limnol Oceanogr 52:2445-2455

* Dagorn L, Bach P, Josse E (2000) Movement patterns of large bigeye tuna (Thunnus obesus) in the open ocean, determined using ultrasonic telemetry. Mar Biol 136:361-371

* Davison PC, Checkley DM, Koslow JA, Barlow J (2013) Carbon export mediated by mesopelagic fishes in the northeast Pacific Ocean. Prog Oceanogr 116:14-30

* De Robertis A (2002) Size-dependent visual predation risk and the timing of vertical migration: an optimization model. Limnol Oceanogr 47:925-933

*Dickson RR (1972) On the relationship between ocean transparency and the depth of sonic scattering layers in the North Atlantic. ICES J Mar Sci 34:416-422

Drazen JC, Sutton TT (2017) Dining in the deep: the feeding ecology of deep-sea fishes. Annu Rev Mar Sci 9:337-366

* Dulvy NK, Rogers SI, Jennings S, Stelzenmüller V, Dye SR, Skjoldal HR (2008) Climate change and deepening of the North Sea fish assemblage: a biotic indicator of warming seas. J Appl Ecol 45:1029-1039

Eggers DM (1977) The nature of prey selection by planktivorous fish. Ecology 58:46-59

Escobar-Flores PC, O'Driscoll RL, Montgomery JC (2018) Spatial and temporal distribution patterns of acoustic backscatter in the New Zealand sector of the Southern Ocean. Mar Ecol Prog Ser 592:19-35

Fiksen O, Giske J (1995) Vertical distribution and population dynamics of copepods by dynamic optimization. ICES J Mar Sci 52:483-503 
Fossheim M, Primicerio R, Johannesen E, Ingvaldsen RB, Aschan MM, Dolgov AV(2015) Recent warming leads to a rapid borealization of fish communities in the Arctic. Nat Clim Chang 5:673-677 7

Freer JJ, Tarling GA, Collins MA, Partridge JC, Genner MJ (2019) Predicting future distributions of lanternfish, a significant ecological resource within the Southern Ocean. Divers Distrib 25:1259-1272

Gislason A (2018) Life cycles and seasonal vertical distributions of copepods in the Iceland Sea. Polar Biol 41: 2575-2589

Gislason A, Silva T (2012) Abundance, composition, and development of zooplankton in the Subarctic Iceland Sea in 2006, 2007, and 2008. ICES J Mar Sci 69:1263-1276

Gjøsæter J (1981) Growth, production and reproduction of the myctophid fish Benthosema glaciale from western Norway and adjacent seas. Fisk Dir Skr Ser Hav Unders 17:79-108

Gjøsaeter J, Kawaguchi K (1980) A review of the world resources of mesopelagic fish. FAO Fish Tech Pap 193: $1-151$

Gjøsæter H, Wiebe PH, Knutsen T, Ingvaldsen RB (2017) Evidence of diel vertical migration of mesopelagic soundscattering organisms in the Arctic. Front Mar Sci 4:1-14

Hays GC (2003) A review of the adaptive significance and ecosystem consequences of zooplankton diel vertical migrations. Hydrobiologia 503:163-170

Heath MR, Astthorsson OS, Dunn J, Ellertsen B and others (2000) Comparative analysis of Calanus finmarchicus demography at locations around the Northeast Atlantic. ICES J Mar Sci 57:1562-1580

*Hernández-León S, Franchy G, Moyano M, Menéndez I, Schmoker C, Putzeys S (2010) Carbon sequestration and zooplankton lunar cycles: Could we be missing a major component of the biological pump? Limnol Oceanogr 55: 2503-2512

Horning M, Trillmich F (1999) Lunar cycles in diel prey migrations exert a stronger effect on the diving of juveniles than adult Galapagos fur seals. Proc Biol Sci 266: 1127-1132

Houston AI, McNamara JM (1999) Models of adaptive behaviour: an approach based on state. Cambridge University Press, Cambridge

Irigoien X, Klevjer TA, Røstad A, Martinez U and others (2014) Large mesopelagic fishes biomass and trophic efficiency in the open ocean. Nat Commun 5:3271

Kaartvedt S, Røstad A, Aksnes DL (2017) Changing weather causes behavioral responses in the lower mesopelagic. Mar Ecol Prog Ser 574:259-263

Kaartvedt S, Langbehn TJ, Aksnes DL (2019) Enlightening the ocean's twilight zone. ICES J Mar Sci doi:10.1093/ icesjms/fsz010

Kampa EM (1971) Photoenvironment and sonic scattering. In: Proceedings of an International Symposium on Biological Sound Scattering in the Ocean Maury Center for Ocean Science. US Government Printing Office, Washington, DC, p 51-59

Kampa EM (1975) Observations of a sonic-scattering layer during the total solar eclipse 30 June, 1973. Deep-Sea Res Oceanogr Abstr 22:417-423

Killen SS, Atkinson D, Glazier DS (2010) The intraspecific scaling of metabolic rate with body mass in fishes depends on lifestyle and temperature. Ecol Lett 13:184-193

Klevjer TA, Irigoien X, Røstad A, Fraile-Nuez E, BenítezBarrios VM, Kaartvedt S (2016) Large scale patterns in vertical distribution and behaviour of mesopelagic scattering layers. Sci Rep 6:19873

Knutsen T, Wiebe PH, Gjøsæter H, Ingvaldsen RB, Lien G (2017) High latitude epipelagic and mesopelagic scattering layers-a reference for future Arctic ecosystem change. Front Mar Sci 4:334

* Koslow JA, Goericke R, Lara-Lopez A, Watson W (2011) Impact of declining intermediate-water oxygen on deepwater fishes in the California Current. Mar Ecol Prog Ser 436:207-218

Kristoffersen JBB, Salvanes AGV (1998) Life history of Maurolicus muelleri in fjordic and oceanic environments. J Fish Biol 53:1324-1341

* Levy DA (1990) Sensory mechanism and selective advantage for diel vertical migration in juvenile Sockeye Salmon, Oncorhynchus nerka. Can J Fish Aquat Sci 47:1796-1802

Mangel M, Clark CW (1988) Dynamic modeling in behavioral ecology. Princeton University Press, Princeton, NJ

Melle W, Ellertsen B, Skjoldal HR (2004) Zooplankton: the link to higher trophic levels. In: Skjoldal HR (ed) The Norwegian Sea ecosystem. Tapir Academic Press Trondheim, Trondheim, p 137-202

Melle W, Runge J, Head E, Plourde S and others (2014) The North Atlantic Ocean as habitat for Calanus finmarchicus: environmental factors and life history traits. Prog Oceanogr 129:244-284

*Naito Y, Costa DP, Adachi T, Robinson PW, Fowler M, Takahashi A (2013) Unravelling the mysteries of a mesopelagic diet: a large apex predator specializes on small prey. Funct Ecol 27:710-717

Netburn AN, Koslow JA (2015) Dissolved oxygen as a constraint on daytime deep scattering layer depth in the southern California current ecosystem. Deep-Sea Res I 104:149-158

Norheim E, Klevjer TA, Aksnes D (2016) Evidence for lightcontrolled migration amplitude of a sound scattering layer in the Norwegian Sea. Mar Ecol Prog Ser 551:45-52

Østvedt OJ (1955) Zooplankton investigations from Weather Ship M in the Norwegian Sea. 1948-49. Hvalrådets Skr 40:1-93

* Pepin P (2013) Distribution and feeding of Benthosema glaciale in the western Labrador Sea: Fish-zooplankton interaction and the consequence to calanoid copepod populations. Deep-Sea Res I 75:119-134

*Pinsky ML, Worm B, Fogarty MJ, Sarmiento JL, Levin SA(2013) Marine taxa track local climate velocities. Science 341:1239-1242

* Prihartato PK, Irigoien X, Genton MG, Kaartvedt S (2016) Global effects of moon phase on nocturnal acoustic scattering layers. Mar Ecol Prog Ser 544:65-75

* Proud R, Cox MJ, Brierley AS (2017) Biogeography of the global ocean's mesopelagic zone. Curr Biol 27:113-119

* Reygondeau G, Guidi L, Beaugrand G, Henson SA and others (2018) Global biogeochemical provinces of the mesopelagic zone. J Biogeogr 45:500-514

* Rosland R, Giske J (1994) A dynamic optimization model of the diel vertical distribution of a pelagic planktivorous fish. Prog Oceanogr 34:1-43

* Røstad A, Kaartvedt S, Aksnes DL (2016a) Light comfort zones of mesopelagic acoustic scattering layers in two contrasting optical environments. Deep-Sea Res I 113:1-6

Røstad A, Kaartvedt S, Aksnes DL (2016b) Erratum to 'Light comfort zones of mesopelagic acoustic scattering layers in two contrasting optical environments' [Deep-Sea Res. I 113 (2016) 1-6]. Deep-Sea Res I 114:162-164 
Sameoto D (1989) Feeding ecology of the lantern fish Benthosema glaciale in a subarctic region. Polar Biol 9:169-178

Saunders RA, Collins MA, Stowasser G, Tarling GA (2017) Southern Ocean mesopelagic fish communities in the Scotia Sea are sustained by mass immigration. Mar Ecol Prog Ser 569:173-185

Sayre RG, Wright DJ, Breyer SP, Butler KA and others (2017) A three-dimensional mapping of the ocean based on environmental data. Oceanography 30:90-103

Scheuerell MD, Schindler DE (2003) Diel vertical migration by juvenile sockeye salmon: empirical evidence for the antipredation window. Ecology 84:1713-1720

Siegelman-Charbit L, Planque B (2016) Abundant mesopelagic fauna at oceanic high latitudes. Mar Ecol Prog Ser 546:277-282

Sims DW, Wearmouth VJ, Southall EJ, Hill JM and others (2006) Hunt warm, rest cool: bioenergetic strategy underlying diel vertical migration of a benthic shark. J Anim Ecol 75:176-190

Sobolevsky YI, Sokolovshaya TG, Balanov AA, Senchenko IA (1996) Distribution and trophic relationships of abundant mesopelagic fishes of the Bering Sea. In: Mathisen OA, Coyle KO (eds) Ecology of the Bering Sea: a review of Russian literature. Alaska Sea Grant Report 96-01

Stewart JD, Barroso A, Butler RH, Munns RJ (2018) Caught at the surface: myctophids make easy prey for dolphins and devil rays. Ecology 99:1894-1896

Sunday JM, Bates AE, Dulvy NK (2012) Thermal tolerance and the global redistribution of animals. Nat Clim Chang 2:686-690

* Sutton TT, Clark MR, Dunn DC, Halpin PN and others (2017) A global biogeographic classification of the mesopelagic zone. Deep-Sea Res I 126:85-102

* Tarling G, Burrows M, Matthews J, Saborowski R, Buchholz F, Bedo A, Mayzaud P (2000) An optimisation model of the diel vertical migration of northern krill (Meganyctiphanes norvegica) in the Clyde Sea and the Kattegat. Can J Fish Aquat Sci 57:38-50

Tont SA (1976) Deep scattering layers: patterns in the Pacific. CCOFI Rep 18:112-117

Tont SA, Wick GL (1973) Response of a deep scattering layer to the 1972 total solar eclipse. Deep-Sea Res Oceanogr Abstr 20:769-771

*Wang Z, DiMarco SF, Ingle S, Belabbassi L, Al-Kharusi LH (2014) Seasonal and annual variability of vertically migrating scattering layers in the northern Arabian Sea. Deep-Sea Res I 90:152-165

* Wurtsbaugh WA, Neverman D (1988) Post-feeding thermotaxis and daily vertical migration in a larval fish. Nature 333:846-848 


\section{Appendix.}
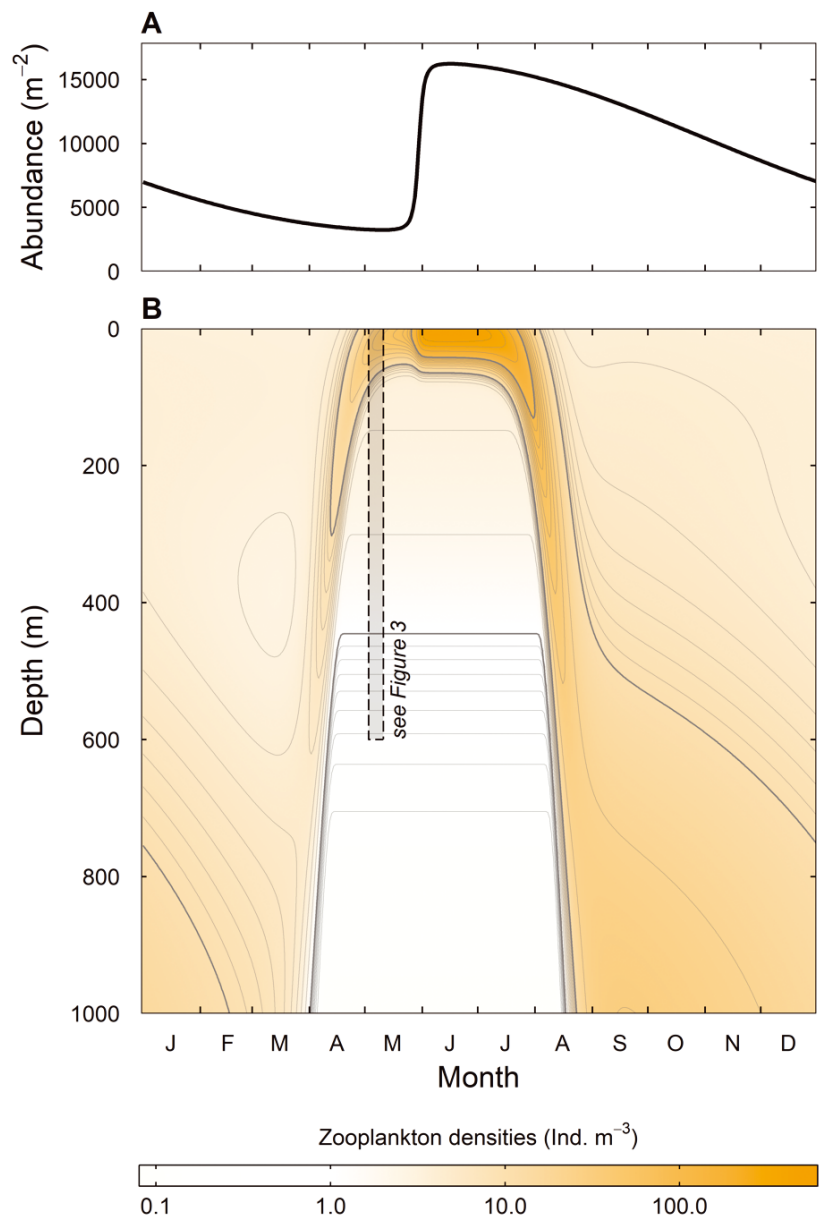

Fig. A1. Idealised zooplankton prey-field for the southern Norwegian Sea used as model input. (A) Seasonally fluctuating zooplankton abundances $\left(\mathrm{m}^{-2}\right.$ summed over the upper $1000 \mathrm{~m})$, and (B) zooplankton densities $\left(\mathrm{m}^{-3}\right)$ compiled from Østvedt (1955), Heath et al. (2000), Melle et al. (2004, 2014), Gislason \& Silva (2012), and Gislason (2018). Note that zooplankton densities are presented on a log-scale. The $0.1,1$ and 10 ind. $\mathrm{m}^{-3}$ isoclines are marked with thick grey lines and the shaded area with a dashed outline indicates the timeframe of the study period

Editorial responsibility: Alejandro Gallego, Aberdeen, UK
Submitted: January 8, 2019; Accepted: June 7, 2019 Proofs received from author(s): July 24, 2019 